Tetrahedron Letters, Volume 54, Issue 39, 25 September 2013, Pages 5338-5340

DOI: $10.1016 /$ j.tetlet.2013.07.106

\title{
A straightforward synthesis of indazolo[3,2-a]isoquinolin-6-amines
}

József Balog, Zsuzsanna Riedl, György Hajós*

Research Center for Natural Sciences, Institute of Organic Chemistry, Hungarian Academy of Sciences, Pusztaszeri út 59, H-1025 Budapest, Hungary

\begin{abstract}
Substituted 1-bromoisoquinolin-3-amines were subjected to Suzuki coupling with $o$-nitrophenylboronic acid to yield 1-(2-nitrophenyl)isoquinolinamines, which participated in Cadogan cyclization with triethyl phosphite under microwave irradiation and pressure to yield fluorescent indazolo[3,2- $a$ ] isoquinolin-6-amines. The new compounds were also functionalized by transformation of the amino group.
\end{abstract}

\section{Keywords}

Suzuki coupling, nitrene, indazole, cyclization, fluorescence

\section{Introduction}

Although significant literature data are available on the reactivity of pyridinamines and its two benzol analogues: 2quinolinamines and 1-isoquinolinamines, ${ }^{1}$ for fewer results have been described on the transformations of isoquinolin3-amines. ${ }^{2}$ An obvious reason being the difficulties in obtaining such amines and the non-straightforward methods for the syntheses of these compounds.

Consideration of novel ring-closure possibilities starting from functionalized isoquinolin-3-amines revealed that 1bromoisoquinolin-3-amine could serve as an excellent starting compound for ring-closure to indazolo[3,2$a$ ]isoquinolines bearing an amino group at position 6. Inspection of the literature revealed that relatively few derivatives of this heteroaromatic ring system have been published. ${ }^{3-6}$ These publications did not describe functional groups on the ring other than a halogen atom.<smiles>[R]c1c(N)nc(Br)c2ccccc12</smiles>

Scheme 1. Retrosynthetic analysis of indazolo[3,2-a]isoquinolin-6-amines (1) from substituted 1-bromoisoquinolin-3amines (4)

*Corresponding author, Tel./fax: +36 14381119.

E-mail address: hajos.gyorgy@ttk.mta.hu 
A possible pathway to the indazolo[3,2- $a$ ] isoquinoline ring system is shown in Schme 1 as a retrosynthetic analysis. Thus, the desired tetracyclic ring (1) could be available by a reductive Cadogan cyclization ${ }^{7}$ of $o$ nitrophenylisoquinoline (3) involving the attack of an intermediate nitrene (2) on the nitrogen atom of the isoquinoline ring. This ring-closure has already been described for one single (unsubstituted) derivative of an indazolo[3,2a] isoquinoline ring, ${ }^{8}$ where the starting compound for the ring-closure was prepared from a 3,4-dihydroisoquinoline derivative in poor yield. ${ }^{9}$ In our synthetic plan, however, the starting compound (3) was to be synthesized by a simple Suzuki coupling of commercially available 1-bromoisoquinolin-3-amine (4) or its easily accessible derivatives ${ }^{10}$ with 2-nitrophenylboronic acid.

Herein we report a concise, two-step reaction to indazolo[3,2-a]isoquinolin-6-amines starting from 4-substituted 1bromoisoquinolin-3-amines as depicted in Scheme 2.

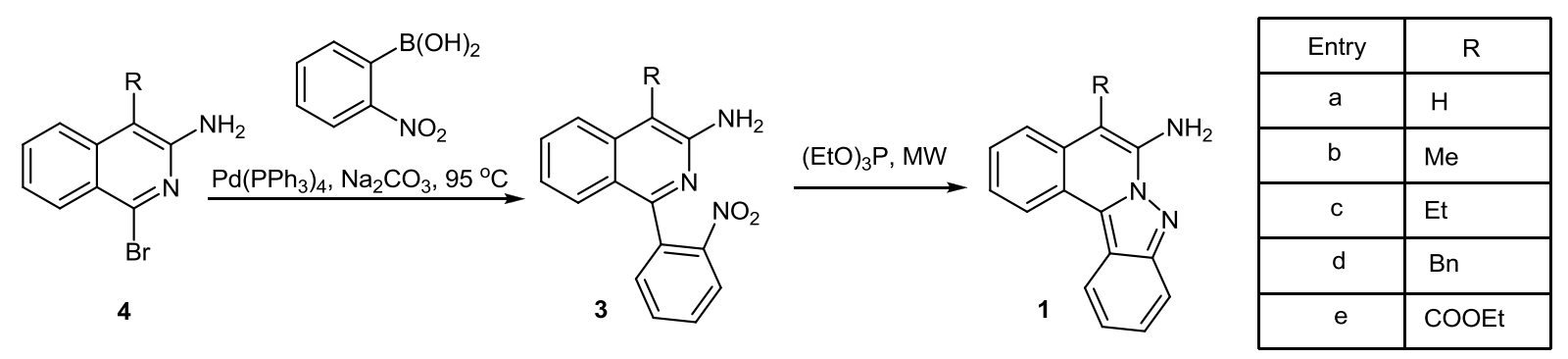

Scheme 2. Two-step synthesis of indazolo[3,2-a]isoquinoline-6-amines (1)

Five different substituted 1-bromoisoquinolin-3-amines (4a-e) were subjected to Suzuki-coupling with 2nitrophenylboronic acid. The best results ${ }^{11}$ were achieved at $95 \quad{ }^{\circ} \mathrm{C}$ with palladium [tetrakis(triphenylphosphine)palladium(0)] as the catalyst and sodium carbonate as base. The new 1-arylisoquinolines (3a-e) were obtained as yellow crystals in high yields(73-92\%). Treatment of compounds (3) with triethyl phosphite under microwave irradiation - in analogy to successful cyclizations of related carbazoles ${ }^{7}$ - resulted in formation of the expected tetracyclic compounds 1a-e in a short reaction time $(20 \mathrm{~min})$ in excellent $79-91 \%$ yields. ${ }^{12}$ The physical characteristics (appearance, mp) and yields of the Suzuki-coupling products 3a-e and the ring-closed indazolo[3,2a] isoquinolin-6-amines 1a-e are summarized in Table 1.

\begin{tabular}{|c|c|c|c|c|c|c|c|}
\hline Product & Color & $\mathrm{mp}\left({ }^{\circ} \mathrm{C}\right)$ & $\begin{array}{l}\text { Yield } \\
(\%)\end{array}$ & Product & Color & $\mathrm{mp}\left({ }^{\circ} \mathrm{C}\right)$ & $\begin{array}{l}\text { Yield } \\
(\%)\end{array}$ \\
\hline 3a & yellow & $154-155$ & 84 & $\mathbf{1 a}$ & yellow & $190-191$ & 91 \\
\hline 3b & red & $157-158$ & 86 & $\mathbf{1 b}$ & yellow & $140-141$ & 79 \\
\hline 3c & orange & $155-156$ & 77 & $\mathbf{1 C}$ & yellow & $150-152$ & 82 \\
\hline 3d & pale orange & $199-201$ & 73 & $\mathbf{1 d}$ & yellow & $183-184$ & 86 \\
\hline 3e & yellow & $165-166$ & 92 & $\mathbf{1 e}$ & yellow & $112-113$ & 86 \\
\hline
\end{tabular}

Table 1. Phisical characteristics (appearance, mp) and yields of the Suzuki-coupling products 3a-e and the ring-closed indazolo[3,2-a]isoquinolin-6-amines 1a-e. 
The reaction proceeds via formation of a reactive electrophilic nitrene which readily attacks the adjacent nucleophilic ring nitrogen atom to givea new five-membered ring. Formation of the new indazolo[2,3- $a$ ]isoquinoline ring system was supported by spectroscopic data (i.e. a downfield shift of the aryl protons in the ${ }^{1} \mathrm{H}-\mathrm{NMR}$ spectra in accordance with the extended aromatic delocalization disappearance of the $\mathrm{NO}_{2}$ absorption in the IR; fundamental change of the UV spectra of $\mathbf{1}$ related to those of $\mathbf{3}$ ).

The new indazoloisoquinoline 1a, interestingly, exhibited fluorescence behaviour with very strong emission intensity (Figure 1.). In acetonitrile, the absorption and fluorescence spectra show approximately mirror symmetry, with stronger vibronic structure in the absorption spectrum a phenomenon which often occurs. The singlet energy is $289 \mathrm{~kJ}$ $\mathrm{mol}^{-1}$ and does not change considerably with the nature of the solvent. Similarly, the fluorescence yield $\left(\Phi_{\mathrm{f}}\right)$, proved to be 0.45 , both in $\mathrm{MeCN}$ and methanol. Acidification of the solvent did not change the appearenceto of the spectra any great extent, except the vibronic structure was lost. However, while the absorption coefficient decreased only slightly after adding $5 \%$ trifluoroacetic acid to the acetonitrile solution (the basicity of the compound is low, consequently a considerable amount of acid is needed to reach full protonation), the fluorescence intensity decreased by two orders of magnitude (Figure 1). This is most probably caused by a protonation-induced internal conversion channel, which competes effectively with the fluorescence.

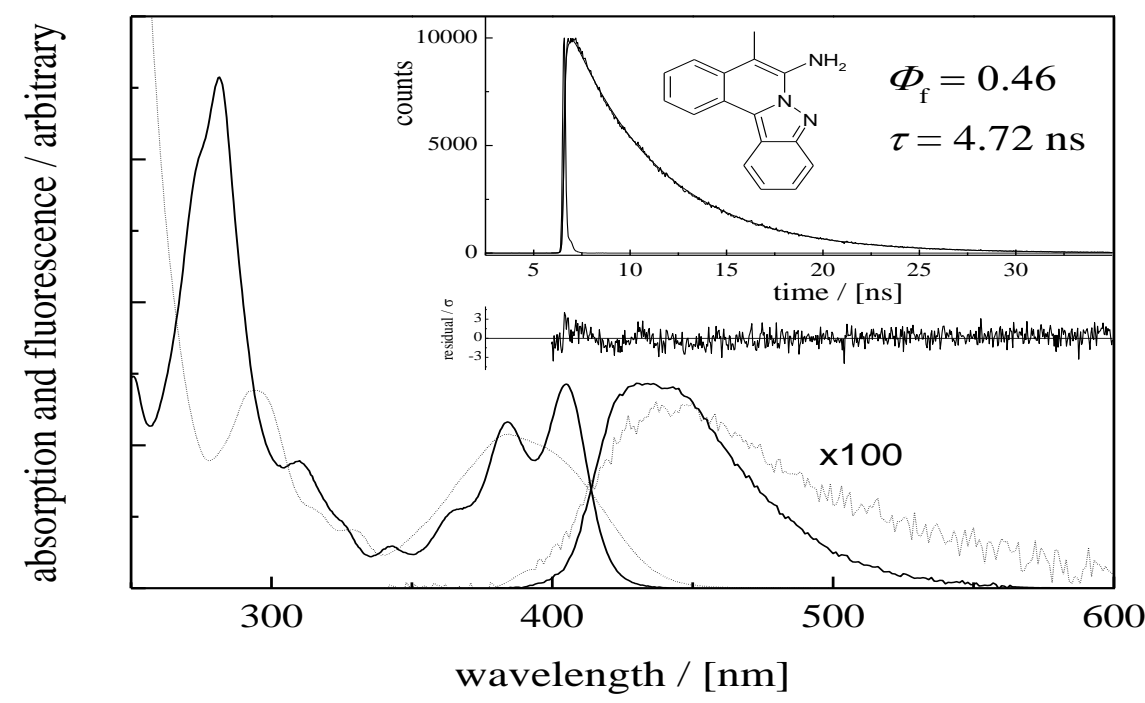

Figure 1. Absorption and fluorescence spectra of $\mathbf{1 a}$ (full lines) and of the protonated form (dotted lines) in acetonitrile at $25{ }^{\circ} \mathrm{C}$ (the weak fluorescence signal of the protonated derivative is multiplied by a factor of one hundred). Inset: fluorescence decay curve of $\mathbf{1 a}$ in acetonitrile measured at $25^{\circ} \mathrm{C}$ (excitation $375 \mathrm{~nm}$, detection $450 \pm 10 \mathrm{~nm}$ ).

The transition probable belongs to the molecular orbitals that have not been influenced by the amino group very much. Furthermore, the dipole moment of the molecule does not seem to change considerably with excitation. The lifetime of the singlet excited state is $4.72 \mathrm{~ns}$ in acetonitrile, while the radiative rate coefficient $\left(k_{\mathrm{f}}=\Phi_{\mathrm{f}} / \tau\right)$ is $9.7 \times 10^{7} \mathrm{~s}^{-1}$. Using this value and the emission spectrum, one the transition dipole moment 3.95 Debye ${ }^{15}$, which is a reasonable value, considering the $\pi-\pi^{*}$ character of the transition mentioned above. In methanol and $n$-hexane the decay parameters, as it is expected, proved to be similar: 4.35 and $4.68 \mathrm{~ns}$, respectively. ${ }^{16}$ 


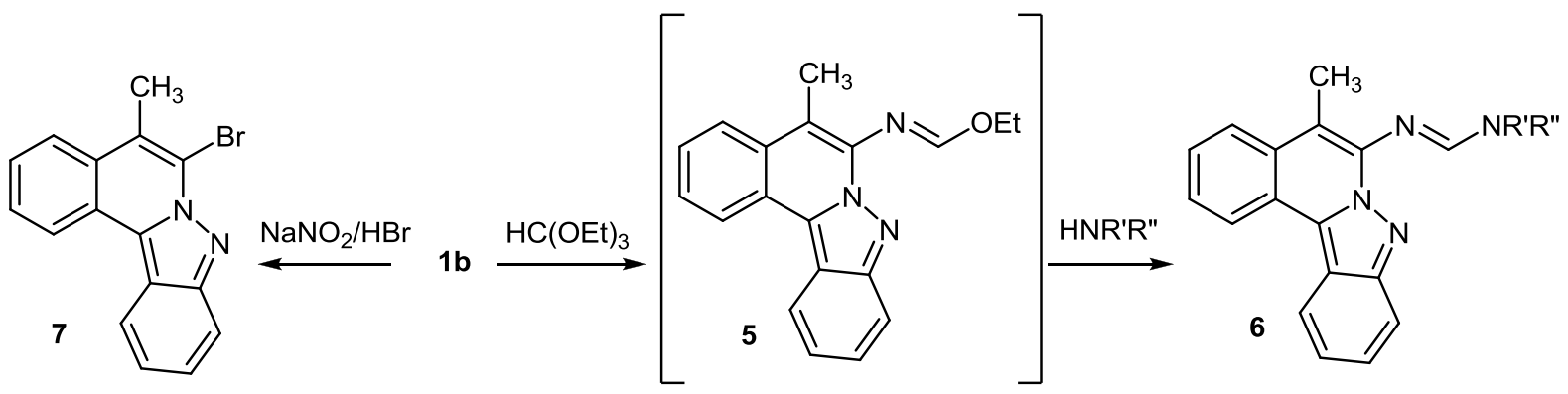

Scheme 3. Transformations of 7-methylindazolo[3,2-a]isoquinolin-6-amine (1b)

To the best of our knowledge, this is the first case that an amino derivative with this ring system has been synthesized. The presence of the amino functionality allows further transformations as shown in Scheme 3. Thus, reaction of $\mathbf{1 b}$ with triethyl orthoformate afforded the imino ether $\mathbf{5}$ which was reacted in situ with secondary amines to give various amidines $\mathbf{6}{ }^{17}$ Furthermore, diazotation of $\mathbf{1 b}$ in hydrobromic acid gave led to formation of 6-bromoindazolo[2,3$a]$ isoquinoline $\left(7,120-121{ }^{\circ} \mathrm{C}, 32 \%\right) .{ }^{18}$

These results reveal that our two-step microwave-assisted ring-closure technique provides a convenient approach to the hitherto sparingly studied indazolo[3,2-a]isoquinoline ring system. Further functionalization of the new ring system is in progress.

\section{References and notes}

${ }^{1}$ N. Dennis, "Pyridines and their Benzo Derivatives: Reactivity of Substituents" in Comprehensive Heterocyclic Chemistry II. ed. by McKillop, A., Elsevier, 1996, 91-134.

${ }^{2}$ For examples, see: (a) Dixit, B.; Balog, J.; Riedl, Zs.; Drahos, L.; Hajos, Gy., Tetrahedron, 2012, 68, 3560. (b) Manley, P. W.; Furet, P.; Bold, G.; Brueggen, J.; Mestan, J.; Meyer, T.; Schnell, C. R.; Wood, J. J. Med. Chem. 2002, 45, 5687. (c) Honda, T.; Mogi, H.; Ban, M.; Aono, H.; Nagahara, H. Bioorg. Med. Chem. Lett., 2011, 21, 1782. (d) Chrzastek, L.; Mianowska, B.; Sliwa, W. Aust. J. Chem., 1994, 47, 2129 .

${ }^{3}$ Zhao, J.; Wu, Ch.; Li, P.; Ai, W.; Chen, H.; Wang, C.; Shi, F.; Larock, R. C. J. Org. Chem. 2011, 76, 6837.

${ }^{4}$ Zhao, J.; Li, Pan; Wu, C.; Chen, H.; Ai, W.; Sun, R.; Ren, H.; Shi, F.; Larock, R. C. Org. Biomol. Chem. 2012, 10, 1922.

${ }^{5}$ Zhang, L.; Xiao, Q.; Ye, S.; Wu, J. Chem. Asian J. 2012, 7, 1909.

${ }^{6}$ Yamashita, Y.; Hayashi, T.; Masumura, M. Chem. Lett. 1980, 1133.

${ }^{7}$ Appukkuttan, P.; Van der Eycken, E.; Dehaen, W. Synlett, 2005, 127.

${ }^{8}$ Stanforth, S. P. J. Heterocyclic Chem. 1987, 24, 531.

${ }^{9}$ Stanley, A. L.; Stanforth, S. P. J. Heterocyclic Chem. 1994, 31, 1399.

${ }_{10}^{10}$ Johnson, F.; Nasutavicus, W. A. J. Org. Chem. 1962, 27, 3953.

${ }^{11}$ Typical procedure for the synthesis of $\mathbf{3}$ by Suzuki coupling of 4: A round-bottomed flask was charged with 1-bromoisoquinolin-3-amine (4a, $0.300 \mathrm{~g}, 1.34 \mathrm{mmol}), 2$-nitrophenylboronic acid (0.268 g, $1.61 \mathrm{mmol}), \mathrm{Pd}\left(\mathrm{PPh}_{3}\right)_{4}(0.077 \mathrm{~g}, 0.067 \mathrm{mmol}, 5 \mathrm{~mol} \%)$, and $\mathrm{Na}_{2} \mathrm{CO}_{3}(0.284 \mathrm{~g}$, $2.68 \mathrm{mmol}$ ) followed by adding toluene $(8 \mathrm{~mL}), \mathrm{EtOH}(4 \mathrm{~mL})$ and $\mathrm{H}_{2} \mathrm{O}(0.5 \mathrm{~mL})$. The mixture was flushed with argon for 5 min and, then, was heated under reflux for $12 \mathrm{~h}$ with magnetic stirring. After cooling to room temperature, the solvent was removed under reduced pressure. The residue was purified by flash column chromatography on silica using hexane/EtOAc (1:1) as the eluent yielding yellow crystals 3a $\left(0.298 \mathrm{~g}, 84 \%, \mathrm{mp} 154-155^{\circ} \mathrm{C}\right)$.

${ }^{12}$ Typical procedure for ring-closure to indazolo[3,2-a]isoquinolin-6-amines $(\mathbf{1})$. The nitrophenyl compound $(\mathbf{3}, 1 \mathrm{mmol})$ was suspended in triethyl phosphite $(4 \mathrm{~mL})$ in a tightly sealed $10 \mathrm{~mL}$ glass vial equipped with a small stirring magnet. The mixture was irradiated in the cavity of an Anton Paar monowave 300 machine for $20 \mathrm{~min}$ at a pre-selected temperature of $200{ }^{\circ} \mathrm{C}$. After completion of the reaction the vial was cooled to $55^{\circ} \mathrm{C}$ by gas jet cooling. The reaction mixture was transferred to a $10 \mathrm{~mL}$ flask and the excess triethyl phosphite was removed under reduced pressure. The residue was treated with hexane and the resulting precipitate was filtered off to give the product. In cases when the mother liquor also contained a substantial amount of product, it was also purified on silica gel.

${ }^{13}$ (a) Demeter, A.; Mile,V.; Bérces, T. J. Phys. Chem. A 2007, 111 (37), 8942; (b) Cserép, G.B.; Enyedi, K.;.Demeter, A.; Mezö, G.; Kele, P. Chem. Asian J. 2013 8, 494.

${ }^{14}$ Kubinyi, M.; Varga, O.; Baranyai, P.; Kállay, M.; Mizsei, R.; Tárkányi, G.; Vidóczy, T. J. Mol. Struct. 2011, 1000, 77.

${ }^{15}$ Lewis, J. E.; Maroncelli, M. Chem. Phys. Lett. 1998, 282, 197.

${ }^{16}$ The absorption spectra were recorded on a thermoregulated Unicam UV500 a spectrophotometer with a resolution of $1 \mathrm{~nm}$. The corrected fluorescence spectra were obtained on a quantum corrected Shimadzu RF-5000PC spectrofluorometer. Excitation wavelength was in the 340$380 \mathrm{~nm}$ range. The room temperature fluorescence quantum yields were determined relative to that of quinine sulfate $\left(\Phi_{\mathrm{f}}=0.546\right)$. In all measurements (except some absorption ones) freeze-pump-thaw degassed samples were used in $1 \times 1 \times 4 \mathrm{~cm}$ Suprasil quartz cells. ${ }^{13}$ The fluorescence decay times were measured at $450 \pm 5 \mathrm{~nm}$ by an Edinburgh Instruments FLS 920 time-resolved spectrofluorimeter, using an EPL-375 semiconductor laser for excitation and a Hamamatsu R3809U-50 MCP-PMT for detection..$^{14}$ All measurements were done at $25^{\circ} \mathrm{C}$. ${ }^{17}$ Synthesis of $(E)-5$-methyl-N-(morpholin-4-ylmethylidene)indazolo[3,2-a] isoquinolin-6-amine (6): A round-bottomed flask was charged with 5-methylindazolo[3,2-a] isoquinolin-6-amine $(\mathbf{1 b}, 0.100 \mathrm{~g}, 0.40 \mathrm{mmol})$, morpholine $(0.500 \mathrm{~g}, 5.74 \mathrm{mmol}, 0.5 \mathrm{~mL})$, triethyl orthoformate $(5 \mathrm{~mL})$ and toluene $(5 \mathrm{~mL})$. The mixture was heated at $110^{\circ} \mathrm{C}$ for $16 \mathrm{~h}$ with stirring. After cooling to room temperature, the excess triethyl orthoformate and toluene were removed in vacuo. The residue was dissolved in $\mathrm{CHCl}_{3}(20 \mathrm{~mL})$ and the solution washed with $\mathrm{H}_{2} \mathrm{O}(20 \mathrm{~mL})$. 
The aqueous phase was extracted with $\mathrm{CHCl}_{3}(2 \times 20 \mathrm{~mL})$ and the combined organic phase dried over anhydrous $\mathrm{Na}_{2} \mathrm{SO}_{4}$. The solution was filtered and evaporated. The residue was triturated with $\mathrm{Et}_{2} \mathrm{O}$ to give a brown powder $(115 \mathrm{mg}, 83 \%), \mathrm{mp} 165-168{ }^{\circ} \mathrm{C}$.

${ }^{18}$ 5-Methylindazolo[3,2-a] isoquinolin-6-amine $(\mathbf{1 b}, 0.300 \mathrm{~g}, 1.21 \mathrm{mmol})$ was dissolved in $48 \%$ aqueous $\mathrm{HBr}(0.86 \mathrm{~mL})$. After cooling to 0 ${ }^{\circ} \mathrm{C}, \mathrm{NaNO}_{2}(0.09 \mathrm{~g}, 1.3 \mathrm{mmol})$ was added slowly to the stirred solution at $0-5{ }^{\circ} \mathrm{C}$. This solution was then poured into a flask containing $\mathrm{CuBr}$ $(0.25 \mathrm{~g}, 1.7 \mathrm{mmol})$ and $48 \%$ aqueous $\mathrm{HBr}(1 \mathrm{~mL})$. The solution was heated to reflux for $3 \mathrm{~h}$, cooled, and poured into $\mathrm{H}_{2} \mathrm{O}$. The aqueous solution was extracted with dichloromethane $(3 \times 30 \mathrm{~mL})$. The organic layer was washed with $1 \mathrm{M} \mathrm{NaOH}(40 \mathrm{~mL})$ and $\mathrm{H}_{2} \mathrm{O}(40 \mathrm{~mL})$ and than dried over $\mathrm{Na}_{2} \mathrm{SO}_{4}$. After removal of the solvent, yellow crystals of 7 were obtained $\left(75 \mathrm{mg}, 20 \%, \mathrm{mp} 193-195{ }^{\circ} \mathrm{C}\right)$. 